\title{
The Proportion of Diploid 46,XX Cells Increases with Time in Women with Turner Syndrome-A 10-Year Follow-Up Study
}

\author{
Anna-Maria Denes, ${ }^{1}$ Kerstin Landin-Wilhelmsen, ${ }^{2}$ Yvonne Wettergren, ${ }^{3}$ Inger Bryman, ${ }^{4}$ and Charles Hanson ${ }^{4}$
}

In the normal population, loss of one of the sex chromosomes leading to monosomy $(45, \mathrm{X})$ is a part of the aging process. In Turner syndrome (TS), the classic karyotype 45,X is found in up to $50 \%$ at birth, and others have a second cell line; mosaicism. The aim was to study if the chromosomal pattern in TS women changes over time. Fluorescence in situ hybridization was performed on buccal smear cells obtained twice, 10 years apart, from 42 women with TS aged 26-66 years (mean \pm standard deviation: 42.0 \pm 11.6 ). DNA probes specific for chromosomes X (DXZ1) and Y (DYZ3) were used and >100 cells were analyzed/patient. Nineteen women had monosomy $(45, \mathrm{X})(<10 \% 46, \mathrm{XX})$, nine had 45,X/46,XX mosaicism, and 14 had iso, ring, or a marker chromosome at baseline. At 10 years, the percentage of diploid cells had increased in 29 of 42 women (69\%), with an average increase of $5.7 \pm 13.0 \%$. There was a positive correlation between age and \% change in diploid $46, \mathrm{XX}$ or $46, \mathrm{XY}$ cells $(r=0.38, p=0.023)$. This new finding might have relevance for the life expectancy in TS.

\section{Introduction}

$\mathbf{S}$ EVERAL STUDIES HAVE consistently found an increase in hypoploidy (loss of one or more chromosomes) related to normal aging in both men and women (Nowinski et al., 1990; Guttenbach et al., 1995; Zietkiewicz et al., 2009; Forsberg et al., 2014). Monosomy of the $\mathrm{X}$ chromosome $(45, \mathrm{X})$ is overrepresented and is the most common chromosomal aberration in women (Guttenbach et al., 1995; Stone and Sandberg, 1995; Wojda et al., 2006; Russell et al., 2007). Some studies have reported an $\sim 10$-fold increase in $\mathrm{X}$ chromosome monosomy in older women (ages $>65$ years) compared with their younger counterparts (ages < 36 years) (Galloway and Buckton, 1978; Martin et al., 1980). It is unclear if the age-related increase in X chromosome hypoploidy is something characteristic of the sex chromosomes or if it is simply a result of a better survival of cells with sex chromosome aberrations compared to cells with autosomal aneuploidy. The viability of cells with $\mathrm{X}$ chromosome hypoploidy is confirmed on an organism level, since it can result in viable individuals with Turner syndrome (TS), whereas autosomal losses result in miscarriage or severe to even lethal pathologies. TS affects one in every 2000-2500 female births (Hook and Warburton, 1983; Nielsen and Wohlert, 1991). The fact that the only existing monosomic state at the organism level is $45, \mathrm{X}$ reflects the lower survival rate of cells with other monosomies and may also explain why monosomic 45, X cells are commonly found in the population. Women with TS have a 10-year shorter life expectancy and an increased prevalence of aortic dissection, especially related to monosomy, compared with women in the general population (Gravholt, 2004; Gravholt et al., 2006).

Nielsen and Krag-Olsen (1980) have shown that 45,X cells have a prolonged cell cycle. Furthermore, chromosomal damages involving specific growth-regulating genes extend the cell cycle time even more. It is believed that there is an in vivo selection against cells with $\mathrm{X}$ chromosome monosomy or other chromosomal aberrations (Nielsen and Krag-Olsen, 1980; Barrenas et al., 2000). In the present study, fluorescence in situ hybridization (FISH) was performed on two occasions, 10 years apart, on buccal cell samples from 42 women with TS. This is the first report of a 10-year longitudinal study in a fairly wide age span of women with TS. The short life expectancy makes it difficult to investigate older TS women than those in the present study. The aim was to study

\footnotetext{
${ }^{1}$ Department of Chemical and Biological Engineering, Chalmers University of Technology, Gothenburg, Sweden.

${ }^{2}$ Section for Endocrinology, Institute of Medicine, Sahlgrenska University Hospital at Sahlgrenska Academy, University of Gothenburg, Gothenburg, Sweden.

${ }^{3}$ Department of Surgery, Institute of Clinical Sciences, Sahlgrenska Academy, University of Gothenburg, Gothenburg, Sweden.

${ }^{4}$ Department of Obstetrics and Gynecology, Institute of Clinical Sciences, Sahlgrenska University Hospital, University of Gothenburg, Gothenburg, Sweden.
}

(C) Anna-Maria Denes et al., 2015; Published by Mary Ann Liebert, Inc. This Open Access article is distributed under the terms of the Creative Commons License Attribution-Non-Commercial Share Alike (http://creativecommons.org/licenses/by-nc-sa/4.0/). 
Table 1. The 45,X Subgroup: Nineteen Women with Turner Syndrome Having < $10 \%$ of Diploid Cells

\begin{tabular}{|c|c|c|c|c|c|c|c|c|c|c|c|}
\hline \multirow{2}{*}{$\begin{array}{l}45, X \\
\text { participant }\end{array}$} & \multirow[b]{2}{*}{ Karyotype } & \multirow{2}{*}{$\begin{array}{l}\text { Age at } \\
\text { year } 10\end{array}$} & \multicolumn{4}{|c|}{ Year 0} & \multicolumn{4}{|c|}{ Year 10} & \multirow{2}{*}{$\begin{array}{c}\% \text { Change } 46, X X \\
\text { or } 46, X Y\end{array}$} \\
\hline & & & $\% X$ & $\% X X$ & $\% X X X$ & $\% X Y$ & $\% X$ & $\% X X$ & $\% X X X$ & $\% X Y$ & \\
\hline 1 & $45, \mathrm{X}$ & 33 & 100 & 0 & 0 & 0 & 97.4 & 2.6 & 0 & 0 & 2.6 \\
\hline 2 & $45, X$ & 33 & 97.8 & 2.2 & 0 & 0 & 98.8 & 1.2 & 0 & 0 & -1 \\
\hline 3 & $45, X$ & 65 & 98.5 & 1.5 & 0 & 0 & 98.3 & 1.7 & 0 & 0 & 0.2 \\
\hline 4 & $45, X$ & 41 & 94.8 & 5.2 & 0 & 0 & 93.6 & 6.4 & 0 & 0 & 1.2 \\
\hline 5 & $45, X$ & 50 & 98.3 & 1.7 & 0 & 0 & 98.5 & 1.5 & 0 & 0 & -0.2 \\
\hline 6 & $45, X$ & 40 & 95.7 & 4.3 & 0 & 0 & 85 & 15 & 0 & 0 & 10.7 \\
\hline 7 & $45, X, \operatorname{inv}(10)(\mathrm{p} 11 ; \mathrm{q} 21)$ & 34 & 96.9 & 3.1 & 0 & 0 & 94.2 & 5.8 & 0 & 0 & 2.7 \\
\hline 8 & $45, X$ & 65 & 99.6 & 0.4 & 0 & 0 & 93.3 & 6.7 & 0 & 0 & 6.3 \\
\hline 9 & $45, X$ & 65 & 98.2 & 1.8 & 0 & 0 & 72.5 & 27.5 & 0 & 0 & 25.7 \\
\hline 10 & $45, \mathrm{X}$ & 36 & 100 & 0 & 0 & 0 & 93.3 & 4.8 & 0 & 1.9 & 6.7 \\
\hline 11 & $45, X$ & 34 & 91.5 & 8.5 & 0 & 0 & 78 & 22 & 0 & 0 & 13.5 \\
\hline 12 & $45, X$ & 34 & 99.6 & 0.4 & 0 & 0 & 97 & 3 & 0 & 0 & 2.6 \\
\hline 13 & $45, X$ & 33 & 96.8 & 3.2 & 0 & 0 & 87 & 13 & 0 & 0 & 9.8 \\
\hline 14 & $45, X$ & 62 & 96 & 3 & 1 & 0 & 96.9 & 3.1 & 0 & 0 & 0.1 \\
\hline 15 & $45, X$ & 36 & 98 & 2 & 0 & 0 & 96 & 4 & 0 & 0 & 2 \\
\hline 16 & $45, X$ & 36 & 93.7 & 6.3 & 0 & 0 & 97 & 3 & 0 & 0 & -3.3 \\
\hline 17 & $45, X$ & 48 & 100 & 0 & 0 & 0 & 97.5 & 2.5 & 0 & 0 & 2.5 \\
\hline 18 & $45, X$ & 26 & 100 & 0 & 0 & 0 & 97.5 & 2.5 & 0 & 0 & 2.5 \\
\hline 19 & $45, X$ & 46 & 100 & 0 & 0 & 0 & 95 & 5 & 0 & 0 & 5 \\
\hline
\end{tabular}

inv, inversion of chromosome.

if the chromosomal pattern changes over time in women with $\mathrm{TS}$, as in the chromosomally normal population.

\section{Materials and Methods}

\section{Participants}

The participants comprised 42 women aged 26-66 years (mean \pm standard deviation [SD]: 42.0 \pm 11.6) diagnosed with TS on the basis of karyotype determination on lymphocytes. The women had been followed since 1995 at the Turner Center in Gothenburg, Sweden and were recruited through an advertisement in the Turner patient magazine, by referral from the hospital, or through transition from the pediatric clinic. They were examined according to the national and international guidelines for care and treatment of patients with TS (Bondy, 2007). The participants were divided into three subgroups based on the genotype labeled " $45, \mathrm{X}$," "mosaic," and "other" (Tables 1-3; Fig. 1) (El-Mansoury et al., 2007). The study was approved by the Ethics Committee at the University of Gothenburg (approval number 242-02), and all participants provided their informed consent.

\section{Karyotypes}

Information on karyotypes for diagnosis was collected from the patient journals. Karyotype analyses were performed on cultured lymphocytes and based on 30 analyzed metaphases.

\section{FISH analysis}

Buccal smears were obtained from all participants at baseline (year 0 ) and after 10 years. The samples were then subjected to interphase FISH analysis with centromeric probes specific for chromosomes X and Y; DXZ1 (Xp11.1q11.1) and DYZ3 (Yp11.1-q11.1), respectively (VYSIS/ Abbott, Inc.). The FISH procedure was conducted as described previously (Hanson et al., 2001a). On average, 150 nuclei were analyzed on each slide, and the proportion of chromosomally abnormal cells was calculated. The repeatability on duplicate samples using the at hand probes was 98.3\%. The same geneticist (C.H.) processed and evaluated all samples on both occasions, in the same laboratory, using the same methodology. The results from the FISH analysis

Table 2. The Mosaic Subgroup: Nine Women with Turner Syndrome Having $\geq 10 \%$ Diploid Cells

\begin{tabular}{|c|c|c|c|c|c|c|c|c|c|c|c|}
\hline \multirow{2}{*}{$\begin{array}{l}\text { Mosaics } \\
\text { participant }\end{array}$} & \multirow[b]{2}{*}{ Karyotype } & \multirow{2}{*}{$\begin{array}{l}\text { Age at } \\
\text { year } 10\end{array}$} & \multicolumn{4}{|c|}{ Year 0} & \multicolumn{4}{|c|}{ Year 10} & \multirow{2}{*}{$\begin{array}{c}\% \text { Change } 46, X X \\
\text { or } 46, X Y\end{array}$} \\
\hline & & & $\% X$ & $\% X X$ & $\% X X X$ & $\% X Y$ & $\% X$ & $\% X X$ & $\% X X X$ & $\% X Y$ & \\
\hline 20 & $45, X / 46, X X$ & 32 & 73.2 & 26.8 & 0 & 0 & 80 & 20 & 0 & 0 & -6.8 \\
\hline 21 & $45, X / 46, X X$ & 41 & 8.5 & 91.5 & 0 & 0 & 4.8 & 95.2 & 0 & 0 & 3.7 \\
\hline 22 & $45, X / 46, X X$ & 30 & 44.9 & 54.6 & 0.5 & 0 & 36 & 64 & 0 & 0 & 9.4 \\
\hline 23 & $45, X / 46, X Y$ & 43 & 66.5 & 0 & 0 & 33.5 & 88.5 & 0 & 0 & 11.5 & -22.5 \\
\hline 24 & $45, X / 46, X X$ & 45 & 5.4 & 92.8 & 1.8 & 0 & 0.8 & 98.5 & 0.8 & 0 & 5.7 \\
\hline 25 & $45, X / 46, X Y$ & 28 & 82 & 0 & 0 & 18 & 70 & 0 & 0 & 30 & 12 \\
\hline 26 & $45, X / 46, X Y$ & 48 & 100 & 0 & 0 & 0 & 97 & 0 & 0 & 3 & 3 \\
\hline 27 & $45, X / 46, X X$ & 42 & 81.5 & 18.5 & 0 & 0 & 85 & 15 & 0 & 0 & -3.5 \\
\hline 28 & $45, X / 46, X X$ & 33 & 6.7 & 93.3 & 0 & 0 & 2.6 & 97.4 & 0 & 0 & 4.1 \\
\hline
\end{tabular}


Table 3. The “Other” Subgroup: Fourteen Women with Turner Syndrome Having Karyotypes, INCLUding ISO, Ring, AND MARKER Y CHROMOSOMES

\begin{tabular}{|c|c|c|c|c|c|c|c|c|c|c|c|}
\hline \multirow{2}{*}{$\begin{array}{l}\text { "Other" } \\
\text { participant }\end{array}$} & \multirow[b]{2}{*}{ Karyotype } & \multirow{2}{*}{$\begin{array}{l}\text { Age at } \\
\text { year } 10\end{array}$} & \multicolumn{4}{|c|}{ Year 0} & \multicolumn{4}{|c|}{ Year 10} & \multirow{2}{*}{$\begin{array}{c}\% \text { Change } 46, X X \\
\text { or } 46, X Y\end{array}$} \\
\hline & & & $\% X$ & $\% X X$ & $\% X X X$ & $\% X Y$ & $\% X$ & $\% X X$ & $\% X X X$ & $\% X Y$ & \\
\hline 29 & $45, X / 46, X, i(X)(q 10)$ & 66 & 25.5 & 74.5 & 0 & 0 & 15.5 & 84.5 & 0 & 0 & 10 \\
\hline 30 & $46, X, X+\operatorname{mar}$ & 29 & 18.7 & 79.2 & 2.1 & 0 & 27 & 73 & 0 & 0 & -6.2 \\
\hline 31 & $45, X / 46, X, i(X)(q 10)$ & 29 & 84.2 & 15.8 & 0 & 0 & 67.7 & 32.3 & 0 & 0 & 16.5 \\
\hline 32 & $45, X / 46, X, \operatorname{der}(Y)$ & 47 & 38 & 0 & 0 & 61 & 22.4 & 0 & 0 & 77.6 & 16.6 \\
\hline 33 & $45, \mathrm{X} / 46, \mathrm{X}, \mathrm{marY}$ & 53 & 86.6 & 0 & 0 & 13.4 & 27 & 0 & 0 & 73 & 59.6 \\
\hline 34 & $46, X,+\operatorname{mar} X$ & 38 & 31.9 & 64.3 & 3.8 & 0 & 34.2 & 65.8 & 0 & 0 & 1.5 \\
\hline 35 & 44X/46,X,i(X)(q11-28) & 51 & 92.9 & 7.1 & 0 & 0 & 80 & 20 & 0 & 0 & 12.9 \\
\hline 36 & $45, \mathrm{X} / 46, \mathrm{XX} / 46, \mathrm{X}, \mathrm{r}(\mathrm{X})$ & 39 & 97.5 & 2.5 & 0 & 0 & 95.5 & 4.5 & 0 & 0 & 2 \\
\hline 37 & $45, X / 46, X X / 46, X, i(X)(q 11-28)$ & 66 & 47.7 & 52.3 & 0 & 0 & 28 & 72 & 0 & 0 & 19.7 \\
\hline 38 & $45, \mathrm{X} / 46, \mathrm{X}, \mathrm{i}(\mathrm{Xq})$ & 34 & 38.6 & 60.4 & 1 & 0 & 67 & 33 & 0 & 0 & -27.4 \\
\hline 39 & $\begin{array}{l}45, X / 46, X, \operatorname{del}(X) \\
\quad(\text { pter } \rightarrow \text { q12::q22 } \rightarrow \text { qter })\end{array}$ & 55 & 30.4 & 66.7 & 2.9 & 0 & 13.5 & 86.5 & 0 & 0 & 19.8 \\
\hline 40 & $45, \mathrm{X} / 46, \mathrm{XX} / 47, \mathrm{XXX}$ & 38 & 58.5 & 2.5 & 38.5 & 0 & 48.9 & 12.8 & 38.3 & 0 & 8 \\
\hline 41 & $45, \mathrm{X} / 46, \mathrm{X}, \mathrm{r}(\mathrm{X})$ & 32 & 53.4 & 46.6 & 0 & 0 & 41 & 59 & 0 & 0 & 12.4 \\
\hline 42 & 45,X/46,X,der(Y) & 50 & 97.7 & 0 & 0 & 2.3 & 99 & 0 & 0 & 1 & -1.3 \\
\hline
\end{tabular}

i, isochromosome; der, derivative chromosome; mar, marker chromosome; r, ring chromosome; del, deletion; pter, short arm; qter, long arm.

were compared with the conventional karyotypes on the lymphocytes.

\section{Statistical analysis}

Mean and SD were calculated according to conventional methods. The individual differences between data obtained at baseline and at 10 years were calculated and tested with Wilcoxon's signed-rank test. The Pearson correlation coefficient $(r)$ was used to compare continuous variables (age and difference in percentage of diploid cells at year 10). A $p$-value $<0.05$ was considered statistically significant.

\section{Results}

The distribution on the three subgroups based on the genotype labeled "45,X," "mosaic," and "other" is shown in Tables 1-3 and Figure 1. The 45, X group included women with $<10 \% 46, X X$-cells at year $0(n=19)$. The mosaic group had $\geq 10 \%$ diploid cells (either $46, \mathrm{XX}$ or $46, \mathrm{XY})(n=9)$. Finally, the "other" group included all other genotypes, such as $\mathrm{i}(\mathrm{X}), \mathrm{r}(\mathrm{X})$, or marker $\mathrm{Y}$ chromosomes $(n=14)$. In two of the women, XY cells were detected during later analyses. In one of these cases, the XY cell line was detected in the original karyotype (one of 10 cells karyotyped) and the woman was thus moved retrospectively to the mosaic group (participant 26, Table 2). However, this change did not influence the results. The other woman was considered as unchanged over time and was thus left in the 45, $\mathrm{X}$ group (participant 10, Table 1).

At 10 years, the percentage of diploid cells had increased in 29 of 42 participants (69\%). Due to limitations of the FISH technique, participants showing changes in cell proportion of $<2 \%$ were considered as unchanged over time; this occurred for participants in the 45,X and "other" groups (Tables 1 and 3; Fig. 1). The percentage differences of diploid cell proportions after 10 years for each of the 42 participants are shown in Figure 2.

The mean proportion of diploid cells increased over time in the whole population of women with TS, from $24.4 \%$ at baseline to $30.1 \%$ after 10 years $(p=0.0002)$; the average increase was $5.7 \pm 13.0$. This trend of increase in diploid cells was also apparent for the subgroups 45,X and "other," in which the mean percentages of diploid cells changed from $2.3 \pm 2.4$ to $7.0 \pm 7.3(p=0.0010)$ and from $39.4 \pm 29.8$ to
FIG. 1. Distribution of the individual differences in $\% \mathrm{XX}$ cells after 10 years in 42 women with Turner syndrome divided into three groups according to genotype: $45, X$, mosaics, and "other" (including iso, ring, deletions, and marker Y chromosomes).

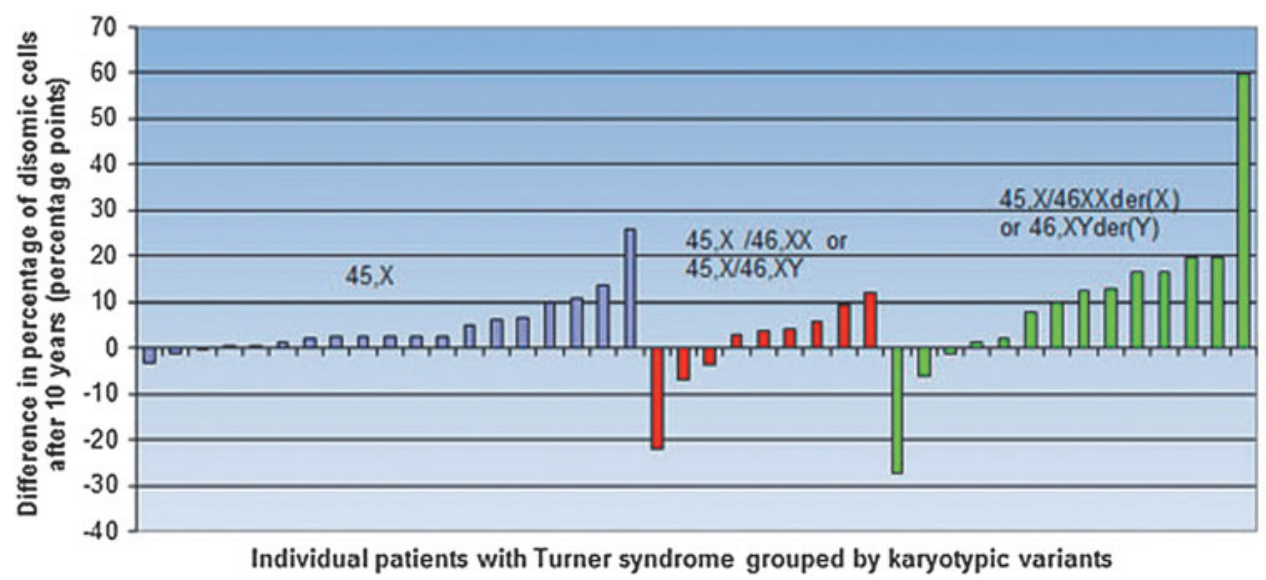




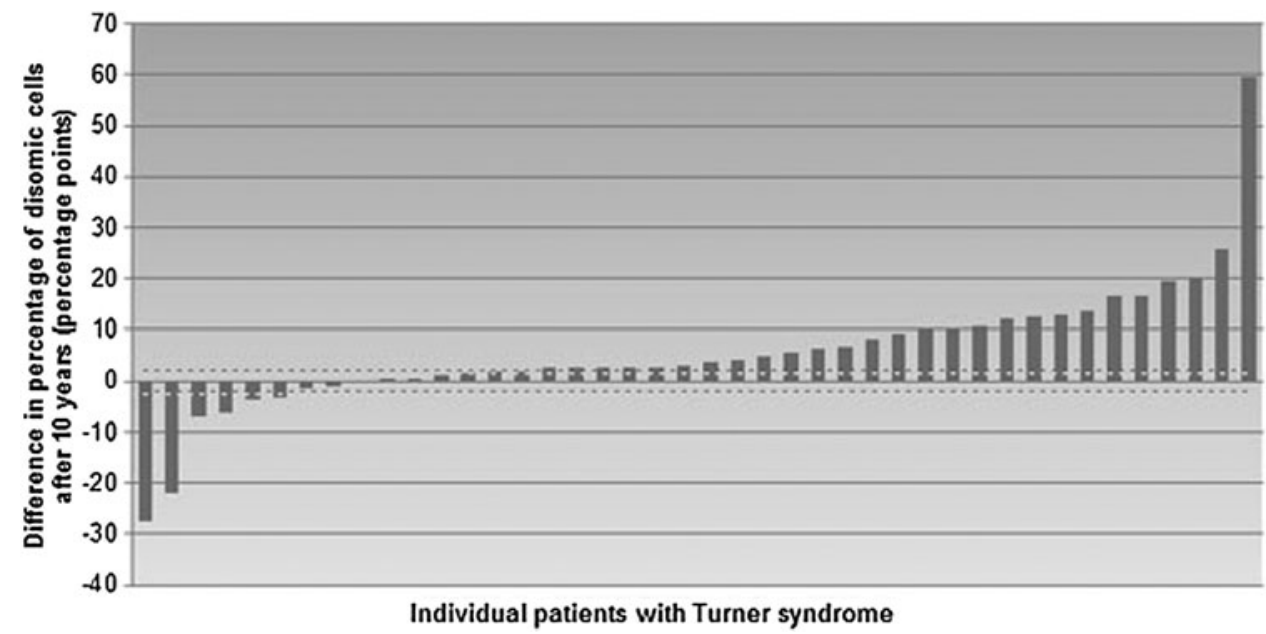

FIG. 2. Distribution of the individual differences in $\%$ XX cells after 10 years in 42 women with Turner syndrome. The dotted line represents the $2 \%$ limit; bars within the dotted lines represent the participants who were considered as unchanged over time.

$49.6 \pm 31.0(p=0.030)$, respectively, after 10 years. However, there was no significant increase of diploid cells in the mosaic subgroup ( $p=0.57)$. Some extreme values were seen in the mosaic and "other" groups. A large negative difference $(-22 \%)$ was found in a woman aged 43 at the last analysis, with XY as the diploid cell line (participant 23, Table 2). In the "other" group, a large negative difference $(-27 \%)$ was found in a mosaic woman aged 34 at the last analysis, with an isochromosome of the q-arm [45,X/ 46,X,i(Xq)] (participant 38, Table 3). A very large positive change $(60 \%)$ was found in a woman aged 53 at the last analysis, with genotype $45, \mathrm{X} / 46, \mathrm{X}$, marY, in whom the proportion of diploid cells rose from $13 \%$ to the remarkable number of $73 \%$ (participant 33, Table 3). In this specific case, the proportion of the diploid cell line was $47 \%$ after 5 years (data not shown).

The correlations between age and \% change in $46, \mathrm{XX}$ or $46, X Y$ cells and between age and $45, X$ cells were analyzed in patients who had a $\geq 2 \%$ change after 10 years of follow-up $(n=35)$. The results showed a significant positive correlation ( $r=0.38, p=0.023)$ between age and \% change in 46,XX or $46, \mathrm{XY}$ cells and a negative correlation $(r=-0.35, p=0.040)$ between age and \% change in $45, \mathrm{X}$ cells. The correlation between age and \% change in $46, \mathrm{XX}$ or $46, \mathrm{XY}$ cells was stronger in women $>36$ years of age compared with women $\leq 36$ years of age (Fig. 3 ).

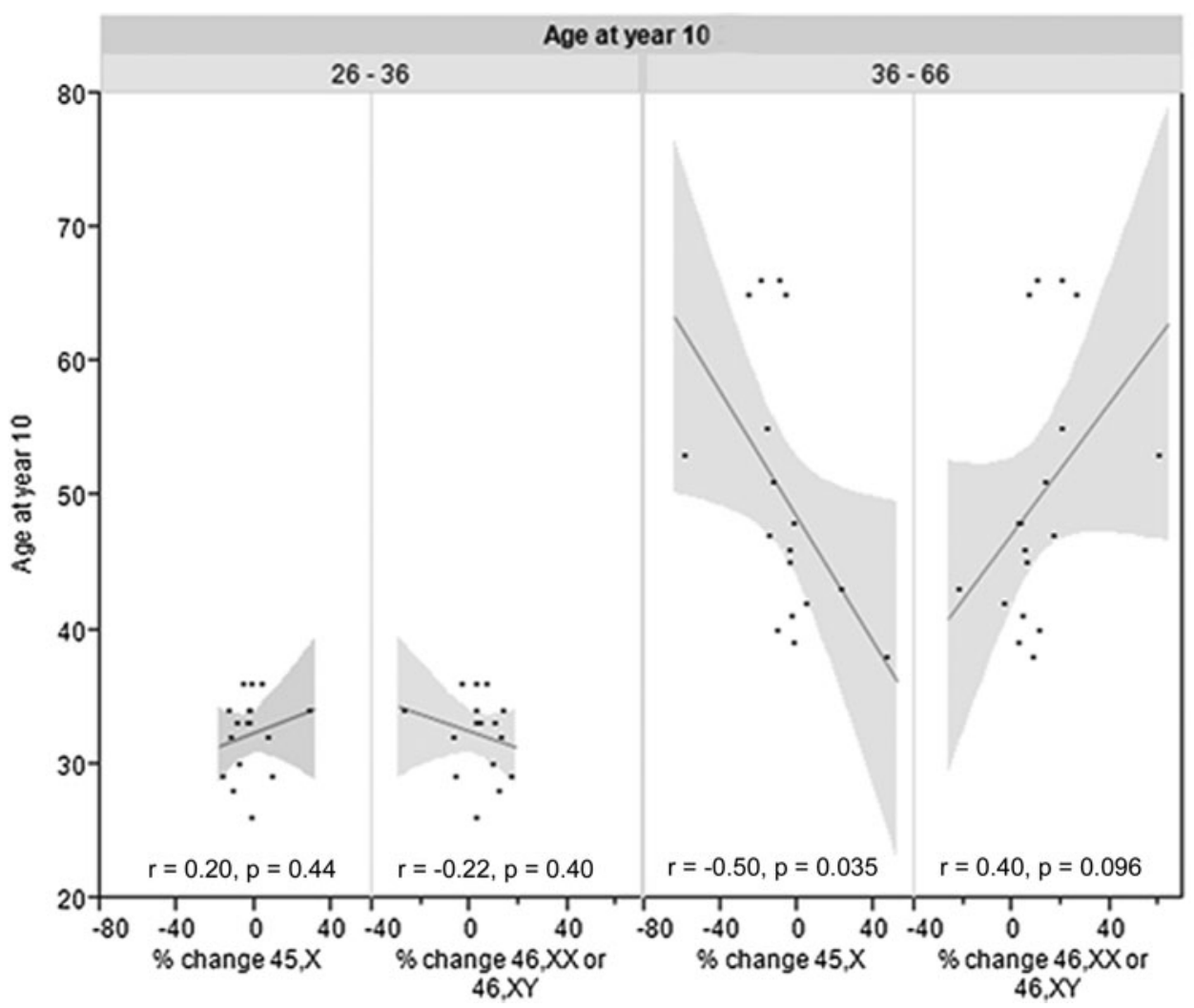

FIG. 3. Correlation between age and $\%$ change in $45, X$ and $46, X X$ or $46, X Y$ cells, respectively, in women with Turner syndrome divided into two age groups: $\leq 36$ years $(n=17)$ and $>36$ years $(n=18)$. Participants with $<2 \%$ change $(n=7)$ were excluded from the analysis. Each line of fit shows a linear regression with confidence intervals. As shown, there was a stronger correlation between age and \% change of $45, X$ and $46, X X$ or $46, X Y$ cells in women $>36$ years of age compared with women $\leq 36$ years of age. 


\section{Discussion}

There was a significant increase in the proportion of diploid cells after 10 years in the whole study population of women with TS. There was a significant positive correlation between age and \% change in diploid cell proportion (Fig. 3) as well as a negative correlation between age and \% change in $45, \mathrm{X}$ cell proportion. The correlations were stronger in women $>36$ years of age compared with women $\leq 36$ years of age. These findings are the opposite of the situation for 46,XX women in the general population (Guttenbach et al., 1995). As it is known that women with TS have a 10 years shorter life expectancy (Gravholt, 2004), the present study was unique in its inclusion of TS women up to fairly high ages. The short life expectancy makes it difficult to investigate TS women older than those in the present study.

In contrast to the majority of participants, a few women showed a decrease in proportion of diploid cells during the 10-year follow-up period (participant 23 in Table 2 and participants 33 and 38 in Table 3 ). These deviations from the overall trend may be due to activated genes on the marker chromosomes influencing the cell survival rate.

Barrenas et al. (2000) proposed a cell cycle delay hypothesis, suggesting a prolonged cell cycle in $45, \mathrm{X}$ cells that would lead to fewer $45, \mathrm{X}$ cells over time as the proportion of $45, \mathrm{X}$ decreased. This is a probable explanation for the increased proportion of diploid cells in the TS women in the present study. Another possible mechanism behind our findings may be related to apoptosis. In a study by Gupta et al. (2003), where T cells from cord blood of a patient with TS were analyzed, an increased apoptosis was observed in the 45, X cells compared with cells from a control.

Concerning the women originally diagnosed to have $45, \mathrm{X}$ cells only, the occurrence of a second diploid cell line later in life may be due to either an originally very low degree of mosaicism (cryptic mosaicism) or the establishment of a second cell line with uniparental disomy (two copies of the chromosome received from only one of the parents and none from the other). With the method used in this study, it was not possible to distinguish between paternally and maternally inherited X chromosomes.

The large variation in genotypes within the participants made it necessary to divide them into subgroups, even though this might jeopardize the proof of significance due to the small sample size. This may be the reason why the mosaic group did not show any significant difference in diploid cell proportion after 10 years, as the group only contained nine individuals. With regard to phenotype, the women in the "other" group were more similar to the women in the $45, \mathrm{X}$ group, meaning that they would gain the most from an increase in diploid cell line, whereas women with mosaicism $(45, \mathrm{X} / 46, \mathrm{XX}$ or $45, \mathrm{X} / 46, \mathrm{XY})$ were expected to be healthier overall and to have less to lose by not having an increase in diploid cells (El-Mansoury et al., 2007).

One limitation of this study was the lack of controls (i.e., women without TS). However, it is well known that the loss of one of the female sex chromosomes is related to normal aging in women (Nowinski et al., 1990; Guttenbach et al., 1995; Zietkiewicz et al., 2009). One strength of the study was that all women with TS were followed for a relatively long time, 10 years, at fairly high ages, and that they were examined by the same staff and with the same methods throughout this time period. Another strength was that the FISH analysis on buccal smears showed concordance with the conventional karyotypes on the lymphocytes.

Most other studies of this kind have used phytohaemagglutininstimulated blood lymphocytes (Russell et al., 2007). However, some have also been performed on cells such as differentiated myeloid cells or buccal mucosal cells with the help of FISH technology (Barrenas et al., 2000; Hanson et al., 2001b). The latter technique was also used in the present study, which was yet another strength, since buccal cells can be studied in vivo and there is no need for culturing of cells (which can affect and thus give an erroneous estimation of true cell line proportion).

Observations made on lymphocytes from children with mixoploid cells showed that the frequency of the abnormal cell line decreased with age (Nielsen and Krag-Olsen, 1980). This appeared to give fewer clinical symptoms compared with children born with the same chromosome abnormalities in all of their cells (Nielsen and Krag-Olsen, 1980). In addition, the level of mosaicism in women with TS is correlated with both the number and seriousness of stigmata (El-Mansoury et al., 2007). For example, cardiac malformations and aortic dissection were more frequently found among women with TS and monosomy than in women with TS who had mosaicism (El-Mansoury et al., 2007). It would therefore be of relevance to investigate whether an increase, decrease, or lack of change in proportion of diploid cells with time has an impact on the phenotype, health, and life expectancy in women with TS.

\section{Conclusions}

The proportion of diploid 46,XX cells increases with time in women with TS, and the \% increase in diploid cell proportion correlates positively with age. The findings are in contrast to the situation in women with $46, \mathrm{XX}$ in the general population, indicating a decreased cell cycle rate and/or an increased apoptosis of chromosomally abnormal 45,X cells. These new findings might have relevance for the life expectancy in women with TS.

\section{Acknowledgments}

The excellent help from midwife Halina Sporrong for coordinating the patients is gratefully acknowledged. This study was supported by grants from the Gothenburg Medical Society and grants from the ALF agreement at the Sahlgrenska University Hospital and the Swedish Council for Working Life and Social Research and Hjalmar Svensson Foundation.

\section{Author Disclosure Statement}

No competing financial interests exist.

\section{References}

Barrenas ML, Landin-Wilhelmsen K, Hanson C (2000) Ear and bearing in relation to genotype and growth in Turner syndrome. Hear Res 144:21-28.

Bondy CA (2007) Care of girls and women with Turner syndrome: a guideline of the Turner Syndrome Study Group. J Clin Endocrinol Metab 92:10-25.

El-Mansoury M, Barrenas ML, Bryman I, et al. (2007) Chromosomal mosaicism mitigates stigmata and cardiovascular 
risk factors in Turner syndrome. Clin Endocrinol (Oxf) 66: 744-751.

Forsberg LA, Rasi C, Malmqvist N, et al. (2014) Mosaic loss of chromosome $\mathrm{Y}$ in peripheral blood is associated with shorter survival and higher risk of cancer. Nat Genet 46:624-630.

Galloway SM, Buckton KE (1978) Aneuploidy and ageing: chromosome studies on a random sample of the population using G-banding. Cytogenet Cell Genet 20:78-95.

Gravholt CH (2004) Epidemiological, endocrine and metabolic features in Turner syndrome. Eur J Endocrinol 151:657-687.

Gravholt CH, Landin-Wilhelmsen K, Stochholm K, et al. (2006) Clinical and epidemiological description of aortic dissection in Turner's syndrome. Cardiol Young 16:430-436.

Gupta S, Chiplunkar S, Gupta A, Gollapudi S (2003) Increased spontaneous, tumor necrosis factor receptor- and CD95 (Fas)mediated apoptosis in cord blood T-cell subsets from Turner's syndrome. Genes Immun 4:239-243.

Guttenbach M, Koschorz B, Bernthaler U, et al. (1995) Sexchromosome loss and aging - in-situ hybridization studies on human interphase nuclei. Am J Hum Genet 57:1143-1150.

Hanson C, Jakobsson AH, Sjogren A, et al. (2001a) Preimplantation genetic diagnosis (PGD): the Gothenburg experience. Acta Obstet Gynecol Scand 80:331-336.

Hanson L, Bryman I, Barrenas ML, et al. (2001b) Genetic analysis of mosaicism in 53 women with Turner syndrome. Hereditas 134:153-159.

Hook EB, Warburton D (1983) The distribution of chromosomal genotypes associated with Turner's syndrome: livebirth prevalence rates and evidence for diminished fetal mortality and severity in genotypes associated with structural $\mathrm{X}$ abnormalities or mosaicism. Hum Genet 64:24-27.

Martin JM, Kellett JM, Kahn J (1980) Aneuploidy in cultured human lymphocytes: I. Age and sex differences. Age Ageing 9:147-153.
Nielsen J, Krag-Olsen B (1980) Cell selection in vivo. Followup of nine unselected mixoploid children. Hum Genet 55: 357-361.

Nielsen J, Wohlert M (1991) Chromosome abnormalities found among 34,910 newborn children: results from a 13-year incidence study in Arhus, Denmark. Hum Genet 87:81-83.

Nowinski GP, Vandyke DL, Tilley BC, et al. (1990) The frequency of aneuploidy in cultured lymphocytes is correlated with age and gender but not with reproductive history. Am J Hum Genet 46:1101-1111.

Russell LM, Strike P, Browne CE, Jacobs PA (2007) X chromosome loss and ageing. Cytogenet Genome Res 116:181185.

Stone JF, Sandberg AA (1995) Sex-chromosome aneuploidy and aging. Mutat Res 338:107-113.

Wojda A, Zietkiewicz E, Mossakowska M, et al. (2006) Correlation between the level of cytogenetic aberrations in cultured human lymphocytes and the age and gender of donors. J Gerontol Biol Sci Med Sci 61A:763-772.

Zietkiewicz E, Wojda A, Witt M (2009) Cytogenetic perspective of ageing and longevity in men and women. J Appl Genet 50:261-273.

Address correspondence to: Charles Hanson, PhD Department of Obstetrics and Gynecology Institute of Clinical Sciences Sahlgrenska University Hospital University of Gothenburg Gothenburg 41345 Sweden

E-mail: charles.hanson@obgyn.gu.se; charles.hanson@fertilitetscentrum.se 